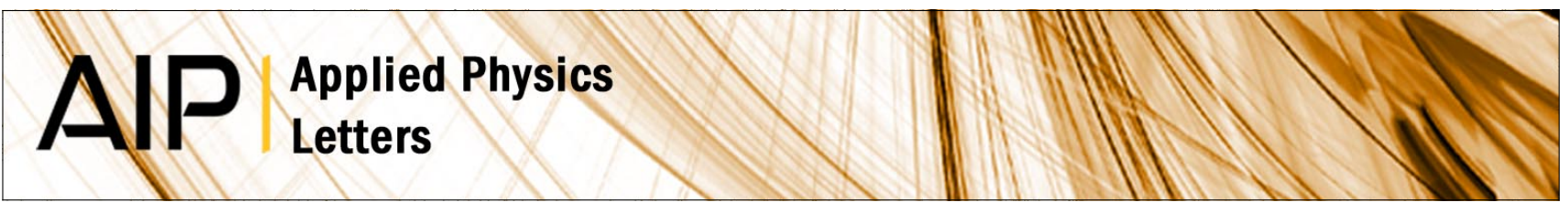

\title{
Doped gallium oxide nanowires with waveguiding behavior
}

Emilio Nogales, José Ángel García, Bianchi Méndez, and Javier Piqueras

Citation: Appl. Phys. Lett. 91, 133108 (2007); doi: 10.1063/1.2790809

View online: http://dx.doi.org/10.1063/1.2790809

View Table of Contents: http://apl.aip.org/resource/1/APPLAB/v91/i13

Published by the American Institute of Physics.

Additional information on Appl. Phys. Lett.

Journal Homepage: http://apl.aip.org/

Journal Information: http://apl.aip.org/about/about_the_journal

Top downloads: http://apl.aip.org/features/most_downloaded

Information for Authors: http://apl.aip.org/authors

\section{ADVERTISEMENT}
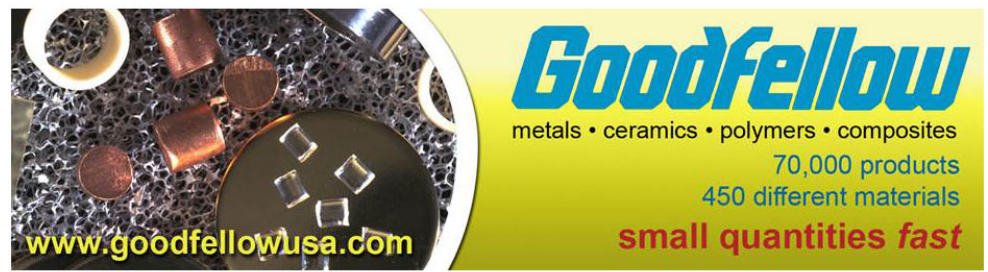


\title{
Doped gallium oxide nanowires with waveguiding behavior
}

\author{
Emilio Nogales ${ }^{a}$ \\ Departamento de Física de Materiales, Universidad Complutense de Madrid, Madrid 28040, Spain \\ José Ángel García \\ Departamento de Física Aplicada II, Apdo. 644, Universidad del País Vasco, Bilbao 48080, Spain
}

Bianchi Méndez and Javier Piqueras

Departamento de Física de Materiales, Universidad Complutense de Madrid, Madrid 28040, Spain

(Received 18 July 2007; accepted 10 September 2007; published online 26 September 2007)

\begin{abstract}
Er and $\mathrm{Cr}$ doped $\beta-\mathrm{Ga}_{2} \mathrm{O}_{3}$ nano- and microwires have been grown by thermal treatments of $\mathrm{Ga}_{2} \mathrm{O}_{3}$ powder containing a fraction of $\mathrm{Er}_{2} \mathrm{O}_{3}$ powder or in the presence of $\mathrm{Cr}_{2} \mathrm{O}_{3}$ powder, respectively. Doping gives rise to the characteristic red photoluminescence (PL) of $\mathrm{Cr}^{3+}$ ions at about $700 \mathrm{~nm}$ and to green emission of $\mathrm{Er}^{3+}$ at about $555 \mathrm{~nm}$. Waveguiding of the ion related PL light excited in the wires has been studied for wires with different sizes. Waveguide behavior for incident visible light of different wavelengths was demonstrated. (C) 2007 American Institute of Physics.
\end{abstract}

[DOI: $10.1063 / 1.2790809$ ]

Bulk and nanostructured semiconductor oxides have been the subject of increasing interest in relation to their applications in optoelectronics, gas sensing, transparent conductors, and others. ${ }^{1}$ In particular, monoclinic gallium oxide $\left(\beta-\mathrm{Ga}_{2} \mathrm{O}_{3}\right)$ with a band gap of about $4.8-5 \mathrm{eV}$ provides the possibility of light emission between the infrared and ultraviolet regions of the spectrum. $\mathrm{Ga}_{2} \mathrm{O}_{3}$ nanowires have been prepared by thermal methods by using different starting materials and substrates. ${ }^{2-10}$ In some cases the nanowires have been doped with different elements, namely, $\mathrm{N},{ }^{6} \mathrm{Zn},{ }^{9}$ or $\mathrm{Cr} .{ }^{10}$ In some of these works ${ }^{3,4,6,8-10}$ the luminescence properties of the doped or undoped nanowires were investigated. An optical property of interest of $\mathrm{Ga}_{2} \mathrm{O}_{3}$ is its high refraction index, of about 1.85-1.91, which makes this material suitable for lightguiding and for optical antireflection coatings. ${ }^{11}$ Waveguiding behavior of crystalline oxide nanowires has been previously studied in few materials such as $\mathrm{SnO}_{2}$ Ref. 12 and $\mathrm{GeO}_{2}{ }^{13}$ In the present work $\mathrm{Ga}_{2} \mathrm{O}_{3}$ nanowires undoped and doped with $\mathrm{Er}$ or $\mathrm{Cr}$ have been grown by a thermal evaporation-deposition method under argon flow. The nanowires have been characterized by x-ray diffraction (XRD), scanning electron microscopy (SEM), and photoluminescence (PL). The waveguiding behavior of the wires for exciting light as well as for the internal photoluminescence signal related to the dopant impurities has been investigated by illumination with light of different wavelengths.

The starting $\mathrm{Ga}_{2} \mathrm{O}_{3}$ material was $99.999 \%$ powder. Samples were prepared by compacting the powder under a compressive load to form disks of about $7 \mathrm{~mm}$ diameter and $2 \mathrm{~mm}$ thickness. They were then annealed under an Ar flow at $1500^{\circ} \mathrm{C}$ for $15 \mathrm{~h}$. This treatment was previously found to cause the growth of nano- and microwires on the disk surface. ${ }^{8}$ For $\mathrm{Cr}$ doping the samples were then annealed for $18 \mathrm{~h}$ at $1500^{\circ} \mathrm{C}$ in an alumina boat in the presence of $\mathrm{Cr}_{2} \mathrm{O}_{3}$ powders (purity $99.999 \%$ ) to obtain chromium incorporation through thermal evaporation and subsequent diffusion into the $\mathrm{Ga}_{2} \mathrm{O}_{3}$. The Er doped samples were prepared from a mixture of $\mathrm{Ga}_{2} \mathrm{O}_{3}$ and 5 at. $\% \mathrm{Er}_{2} \mathrm{O}_{3}$ (purity 99.999\%) powders which was mechanically milled for $30 \mathrm{~h}$. The milled mixture was compacted and annealed under argon flow at $1500^{\circ} \mathrm{C}$ for $15 \mathrm{~h}$, as will be detailed elsewhere. All the samples were characterized by $\mathrm{x}$-ray diffraction to assess the crystalline structure. SEM investigations were carried out in a Leica 440 scanning electron microscope. For the waveguide measurements with an optical microscope the wires were gently detached from the sample on a high purity glass substrate and illuminated either with a light emitting diode (LED) with peak at $470 \mathrm{~nm}$, lasers of wavelength 531 or $652 \mathrm{~nm}$, or with the $366 \mathrm{~nm}(3.39 \mathrm{eV})$ or $436 \mathrm{~nm}(2.84 \mathrm{eV})$ emission lines of a Hg lamp. The spectra of the light emitted at the ends of the wires were recorded at room temperature (RT) either with an Edinburgh Instruments or a Spex 750M monochromators. The recorded light in the images is either the excitation light, which is guided through the wire, or the photoluminescence emission excited in the wire by the incident laser or $\mathrm{Hg}$ lamp, and guided into both ends.

Nanowires with diameters from tens of nanometers to few microns and lengths from several microns to tens of microns grow on the surface of the undoped and doped samples. Figure 1 shows an example of the obtained nanowires.

In some cases the wires form more complex arrangements as comblike structures, as reported in Ref. 8. Luminescence spectra at different temperatures of $\mathrm{Cr}$ doped samples have already been reported. ${ }^{8,10}$ At room temperature the spectra show red emission, which is the superposition of the $\mathrm{Cr}^{3+}$ related sharp $R$ lines, ${ }^{2} E-{ }^{4} A_{2}$ transition, and its pho-

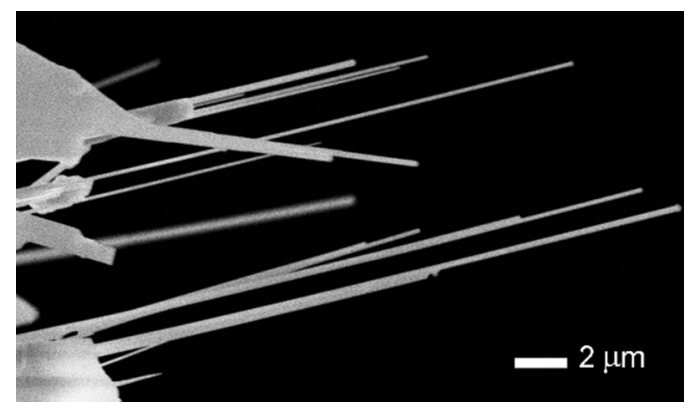

FIG. 1. SEM image of the obtained $\beta-\mathrm{Ga}_{2} \mathrm{O}_{3}$ nanowires.

a)Electronic mail: emilio.nogales@fis.ucm.es 

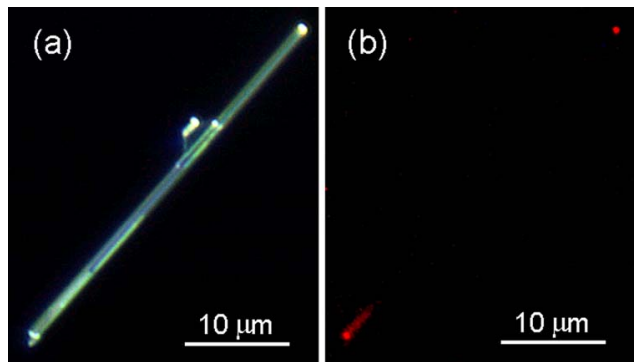

FIG. 2. (Color online) (a) Optical image of a Cr doped wire and (b) RT micro-PL image of the wire illuminated with the $436 \mathrm{~nm}$ line of the $\mathrm{Hg}$ lamp in the lower end. Red $\mathrm{Cr}$ luminescence is excited in this end and transmitted along the wire.

non assisted broad ${ }^{4} T_{2}{ }^{4} A_{2}$ band. ${ }^{10}$ Energy dispersive x-ray microanalysis revealed that these samples have a $\mathrm{Cr}$ content of about 1 at. \%. Nominally undoped samples often show a less intense red emission due to contamination during the growth process.

$\mathrm{Cr}$ doped wires of different sizes were excited with the $436 \mathrm{~nm}(2.84 \mathrm{eV})$ line of the $\mathrm{Hg}$ lamp, which corresponds to the main peak of the excitation spectrum of the $696 \mathrm{~nm} \mathrm{Cr}$ line. ${ }^{10}$ Under illumination, intense red spots are observed at the ends of the wires showing the waveguiding of the red $\mathrm{Cr}$ emission. Figure 2(a) shows the optical image of a wire of $40 \mu \mathrm{m}$ length and $1.5 \mu \mathrm{m}$ width and Fig. 2(b) shows the RT micro-PL image of the wire excited with $436 \mathrm{~nm}$ light at one end, in the lower part of the image, and the intense red exit spot in the opposite end.

Waveguiding is also clearly observed when the whole wires, especially the larger ones, are illuminated. This is shown in Fig. 3(a) for a wire about $7.5 \mu \mathrm{m}$ long, but similar images are recorded for wires with lengths of tens of microns. Figure 3(b) shows a wire of about $2 \mu \mathrm{m}$ length, and cross-sectional dimension of about $600-700 \mathrm{~nm}$, in which the waveguide effect is scarcely revealed. PL spectra of the light generated and transmitted along the wires have been found to depend on their size. Figure 4 shows the spectra from three wires with different lengths and cross-sectional dimensions. Figure 4(a) shows the spectrum of a wire of $40 \mu \mathrm{m}$ length and about $1.3 \mu \mathrm{m}$ width. The $R$ lines of $\mathrm{Cr}$ are well resolved on the broad red band which is intense at room temperature. ${ }^{8,10}$ In the spectrum of Fig. 4(b), which corresponds to a wire with similar cross section but with a length of $80 \mu \mathrm{m}$, the lines appear less sharp and with a lower relative intensity. Figure 4(c) shows the spectrum of the small wire shown in Fig. 3(b), whose cross-sectional dimension is $600-700 \mathrm{~nm}$, in which the $R$ lines are only poorly resolved.

Comparison of Figs. 4(a) and 4(b) shows that by increasing the length of the wire the $R$ lines appear less resolved possibly due to scattering and absorption processes. Figure 4(c) shows a marked relative increase of the intensity in the
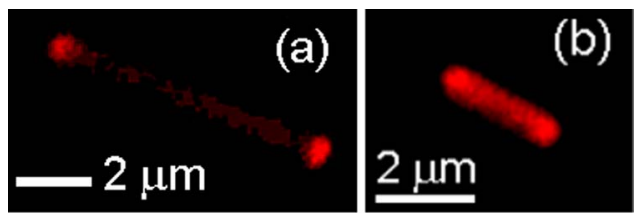

FIG. 3. (Color online) Room temperature micro-PL images of $\mathrm{Cr}$ doped wires. $\lambda_{\text {exc }}=436 \mathrm{~nm}$. (a) Waveguiding behavior and (b) slight waveguiding effect in a wire of smaller dimensions.
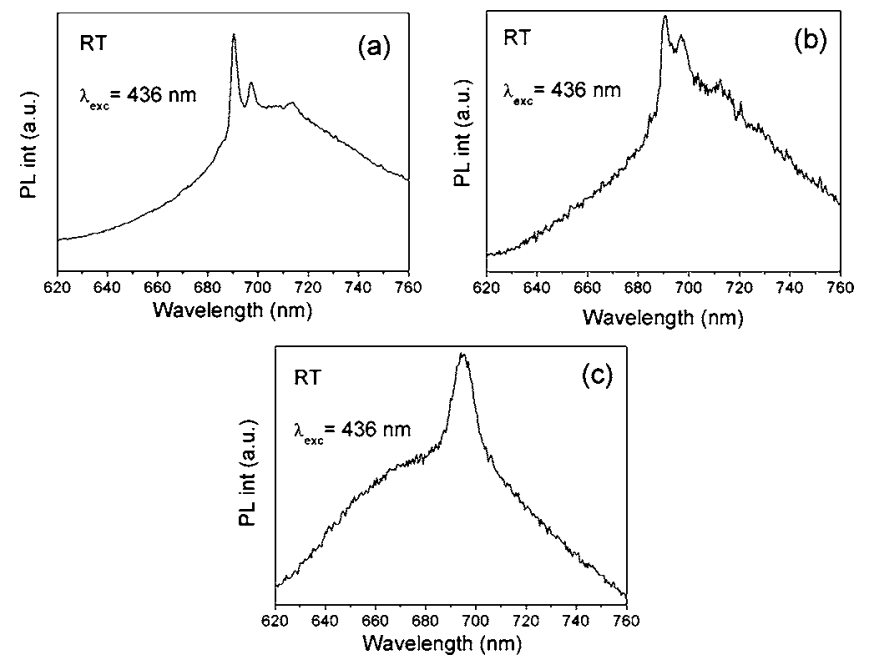

FIG. 4. Room temperature PL spectra of Cr doped wires. $\lambda_{\text {exc }}=436 \mathrm{~nm}$. (a) Wire with $40 \mu \mathrm{m}$ length and cross-sectional dimensions of about $1.3 \mu \mathrm{m}$. (b) Wire with similar transversal dimension as that shown in (a) and a length of $80 \mu \mathrm{m}$. (c) Wire of $2 \mu \mathrm{m}$ length and a transversal dimension of $600-700 \mathrm{~nm}$.

short wavelength side of the spectrum, which is suggested to be related to the nanowire size. Since the cross-sectional dimension of the nanowire is about $600-700 \mathrm{~nm}$, one would expect that the optical loss for wavelengths of this and higher values is larger than for shorter wavelengths. A similar effect has been reported in a study on $\mathrm{SnO}_{2}$ (Ref. 12) in which it was found that large wires act as waveguides across the visible spectrum while thin wires do not propagate red light or propagate it only over short distances.

Figure 5 shows the dark field and micro-PL images of a wire end from the Er doped sample and its corresponding PL spectrum at RT, recorded under excitation with $366 \mathrm{~nm}$. Illumination of Er doped samples with this wavelength, which corresponds to a strong peak of the excitation spectrum of the Er ions in this host, produces intense green luminescence which is propagated in the wire. This emission is due to the ${ }^{4} S_{3 / 2}{ }^{4} I_{15 / 2}$ intraionic transition and presents the typical sharp peaked structure, as shown in Fig. 5(c). As it will be reported elsewhere, XRD reveals that the Er doped samples contain,
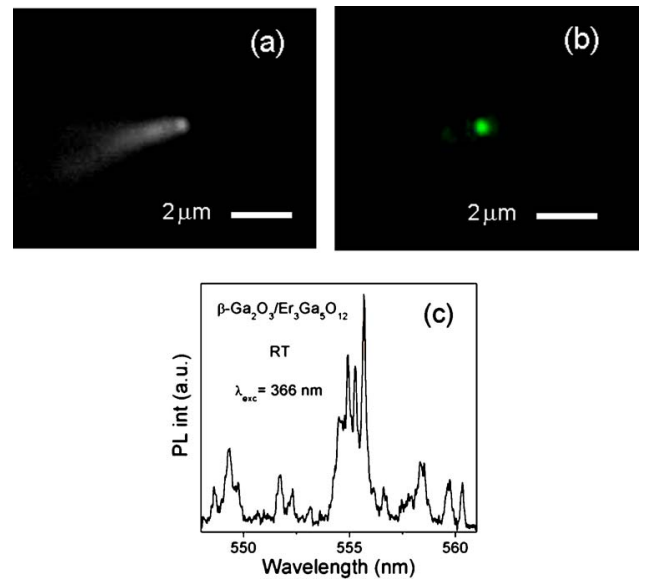

FIG. 5. (Color online) (a) Optical image and (b) room temperature micro-PL image of the end of a wire in erbium doped $\beta-\mathrm{Ga}_{2} \mathrm{O}_{3}$ sample. (c) Corresponding room temperature PL spectrum showing that the observed green emission in (b) is due to the $\mathrm{Er}^{3+}$ intraionic transitions. $\lambda_{\mathrm{exc}}$ in (b) and (c) was $366 \mathrm{~nm}$. 

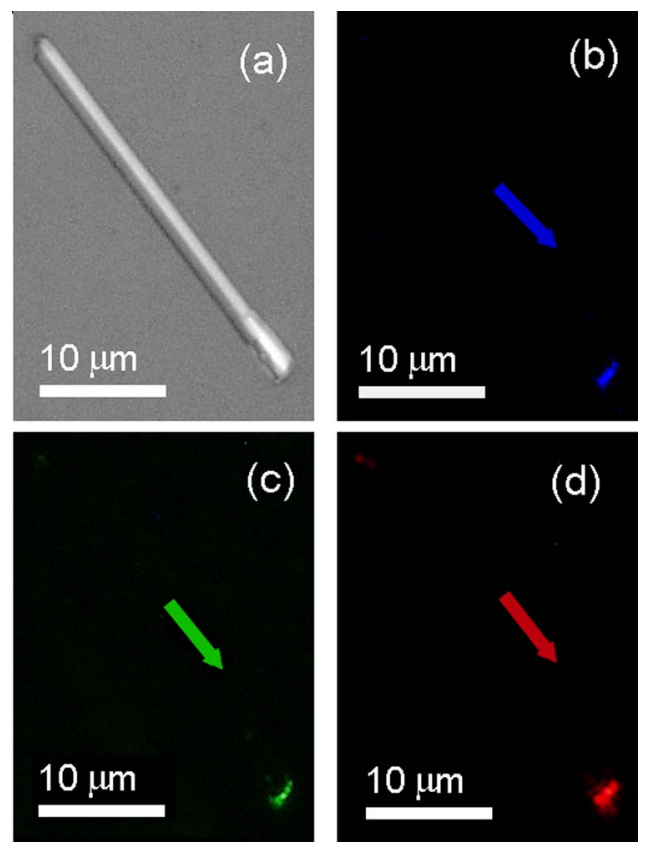

FIG. 6. (Color online) (a) Optical image and transmission of (b) blue (LED with peak at $470 \mathrm{~nm}$ ), (c) green (laser with peak at $531 \mathrm{~nm}$ ), and (d) red (laser with peak at $652 \mathrm{~nm}$ ) light through a $2 \times 33 \mu \mathrm{m}^{2}$ wire. Arrows indicate the direction in which light propagates.

in addition to the main monoclinic $\beta-\mathrm{Ga}_{2} \mathrm{O}_{3}$ phase, erbium gallium garnet $\left(\mathrm{Er}_{3} \mathrm{Ga}_{5} \mathrm{O}_{12}\right)$ which is related to the strong green emission of Er.

We have also observed the transmission of the incident light through undoped as well as Er and $\mathrm{Cr}$ doped $\beta-\mathrm{Ga}_{2} \mathrm{O}_{3}$ wires. For this purpose, we illuminated the wires with blue, green, or red light with wavelengths different from the absorption peaks of chromium or erbium ions and nearly parallel to their growth direction (Fig. 6). The only light that we collect with the optical microscope arises from the wire end which is opposite to the light source, which indicates that we are collecting light that has been guided through it.
The blue light source was a LED with a peak wavelength at $470 \mathrm{~nm}$, while lasers with peaks at 531 and $652 \mathrm{~nm}$ were used for illumination in green and red, respectively.

Summarizing, undoped as well as $\mathrm{Cr}$ and $\mathrm{Er}$ doped $\mathrm{Ga}_{2} \mathrm{O}_{3}$ nano- and microwires have been grown by thermal treatments at $1500^{\circ} \mathrm{C}$ under argon flow. The wires show waveguiding behavior for the dopant ion luminescence light. The room temperature spectra of the propagated light depend on the dimensions of the wire. In particular, for wires with cross-sectional dimensions down to 600-700 nm, the characteristic red $R$ lines of $\mathrm{Cr}^{3+}$ are not resolved and the spectra show a blueshift. The wires act as waveguides for incident red, green, and blue light at energies not corresponding to the excitation of $\mathrm{Er}$ or $\mathrm{Cr}$ ions.

This work has been supported by MEC (Project No. MAT 2006-01259).

${ }^{1}$ Z. W. Pan, Z. R. Dai, and Z. L. Wang, Science 291, 1947 (2001).

${ }^{2}$ J. H. Zhan, Y. Bando, J. Q. Hu, F. F. Xu, and Q. Golberg, Small 1, 883 (2005).

${ }^{3}$ X. C. Wu, W. H. Song, W. D. Huang, M. H. Pu, B. Zhao, Y. P. Sun, and J. J. Du, Chem. Phys. Lett. 328, 5 (2000).

${ }^{4}$ D. P. Yu, J.-L. Bubendorff, J. F. Zhou, Y. Leprince-Wang, and M. Troyon, Solid State Commun. 124, 417 (2002).

${ }^{5}$ K.-W. Chang and J.-J. Wu, Adv. Mater. (Weinheim, Ger.) 16, 545 (2004).

${ }^{6}$ Y. P. Song, H. Z. Zhang, C. Lin, Y. W. Zhu, G. H. Li, F. H. Yang, and D. P. Yu, Phys. Rev. B 69, 075304 (2004).

${ }^{7}$ Z. X. Yang, F. Zhu, Y. J. Wu, W. Zhou, and Y. F. Zhang, Physica E (Amsterdam) 27, 351. (2005)

${ }^{8}$ E. Nogales, B. Méndez, and J. Piqueras, Appl. Phys. Lett. 86, 113112 (2005).

${ }^{9}$ P. C. Chang, Z. Fan, W. Y. Tseng, A. Rajagopal, and J. G. Lu, Appl. Phys. Lett. 87, 222102 (2005).

${ }^{10}$ E. Nogales, J. A. García, B. Méndez, and J. Piqueras, J. Appl. Phys. 101, 033517 (2007)

${ }^{11}$ M. Passlack, E. F. Schubert, W. S. Hobson, M. Hong, N. Moriya, S. N. G. Chu, K. Konstadinidis, J. P. Mannaerts, M. L. Schnoes, and G. J. Zydzik, J. Appl. Phys. 77, 686 (1995).

${ }^{12}$ M. Law, D. J. Sirbuly, J. C. Johnson, J. Goldberger, R. J. Saykally, and P. Yang, Science 305, 1269 (2004).

${ }^{13}$ P. Hidalgo, B. Méndez, and J. Piqueras, Nanotechnology 18, 155203 (2007). 